Shonfield, J., and E. M. Bayne. 2017. The effect of industrial noise on owl occupancy in the boreal forest at multiple spatial scales. Avian

Conservation and Ecology 12(2):13. https://doi.org/10.5751/ACE-01042-120213

Copyright (C) 2017 by the author(s). Published here under license by the Resilience Alliance.

Research Paper

\title{
The effect of industrial noise on owl occupancy in the boreal forest at multiple spatial scales
}

\author{
Julia Shonfield ${ }^{1}$ and Erin M. Bayne ${ }^{1}$ \\ ${ }^{1}$ Department of Biological Sciences, University of Alberta
}

\begin{abstract}
Noise in natural environments can mask important acoustic signals used for animal communication. Owls use vocal communication to attract mates and defend territories, and also rely on acoustic cues to locate their prey. Industrial noise has been shown to negatively affect owl hunting success and reduce foraging efficiency by affecting their ability to detect prey, but it is not known if this results in reduced habitat suitability for owls in areas near industrial noise sources. To determine if owls avoid areas surrounding industrial noise sources in northeastern Alberta and at what scale, we acoustically surveyed for owls at sites with chronic industrial noise, sites with intermittent traffic noise, and sites with no noise. We deployed autonomous recording units at multiple stations within each site to detect territorial individuals vocalizing. Detections of owls were extracted from the recordings using automated species recognition and analyzed using occupancy models at two spatial scales. Barred Owls (Strix varia), Great Horned Owls (Bubo virginianus), and Boreal Owls (Aegolius funereus) were equally likely to occupy both types of noisy sites compared to sites with no noise, indicating that site level occupancy (representing a home range scale) was unaffected by the presence of noise sources on the landscape. On a smaller scale, there was no decline in station level occupancy (representing use of the area surrounding recording stations) at stations with higher noise levels for either of the three owl species. Our study contributes to research on the effects of anthropogenic noise, but suggests the effect on owls is minimal, and unlikely to result in a population change.
\end{abstract}

\section{Effets du bruit industriel sur l'occupation de l'habitat par des hiboux dans la forêt boréale à de multiples échelles spatiales}

RÉSUMÉ. Le bruit dans l'environnement naturel peut masquer d'importants signaux acoustiques de communication animale. Les hiboux utilisent les communications vocales afin d'attirer un partenaire et pour défendre un territoire, et aussi ils dépendent de leur acuité auditive afin de localiser leurs proies. Il a été démontré que le bruit industriel affecte négativement le succès de chasse des hiboux et diminue l'efficacité d'acquisition de nourriture en affectant leur capacité à détecter les proies, mais on ne sait pas si cela se traduit par une réduction de l'habitat convenable pour les hiboux dans les zones près des sources de bruit industriel. Afin de déterminer si les hiboux évitent les zones entourant les sources de bruit industriel au nord-est de l'Alberta, et à quelle échelle, nous avons échantillonné acoustiquement des sites à bruits industriels chroniques, des sites à bruits intermittents, ainsi que des sites sans bruit. Nous avons déployés des unités autonomes d'enregistrement à plusieurs stations dans chaque site afin de détecter des individus vocalisant dans leur territoire. Les vocalisations de hiboux détectées furent extraites des enregistrements par un système de reconnaissance de l'espèce automatisé et analysé par modèles d'occupation de l'habitat sur deux échelles spatiales. La Chouette Rayée (Strix varia), le Grand-duc d'Amérique (Bubo virginianus), et le Nyctale de Tengmalm (Aegolius funereus) occupaient également les deux types de sites bruyants comparativement aux sites sans bruit, ce qui indique qu'une occupation au niveau du site (échelle du domaine vital) n'a pas été affecté par la présence de bruit au niveau du paysage. À une plus petite échelle, aucune dimunition de l'occupation au niveau de la station (représentant l'utilisation de l'habitat autour des stations d'enregistrements) dans les stations affichant des niveaux de bruit plus élevés pour l'une ou l'autre des trois espèces. Notre étude contribue à la recherche sur les effets du bruit anthropique, mais suggère que l'effet sur les hiboux est minime et qu'il soit peu probable de que ceci contribu à un changement de population.

Key Words: acoustic masking; anthropogenic noise; automated species recognition; autonomous recording units; Barred Owl; Boreal Owl; Great Horned Owl

\section{INTRODUCTION}

Noise in an environment can affect animal communication by reducing a receiver's ability to detect important signals as background noise increases, a phenomenon known as "acoustic masking" (Francis et al. 2011a). One source of acoustic masking is anthropogenic noise; increased transportation, urban sprawl, and industrial development are all contributing to create noisier landscapes. Noise can be infrequent and may trigger startle responses in animals, or noise can be chronic and potentially interfere with signal detection (Francis and Barber 2013). A growing body of research seeks to understand the effects of anthropogenic noise on animals (reviewed in Brumm and Slabbekoorn 2005, Barber et al. 2010, Francis and Barber 2013). The majority of studies have documented effects of noise (Shannon et al. 2016), including noise-induced changes to animal signals (Slabbekoorn and Peet 2003, Francis et al. 2011b) and

Address of Correspondent: Julia Shonfield, Department of Biological Sciences, CW 405 Biological Sciences Building, University of Alberta, Edmonton, AB Canada T6G 2E9, julia.shonfield@gmail.com 
decreases in animal abundance and diversity (Bayne et al. 2008, Francis et al. 2009, McClure et al. 2013). This suggests that communication is strongly affected by noise, causing some species to alter their signals and some to avoid noisy areas altogether.

Owls (Strigiformes) use vocal communication to attract mates and defend territories. When hunting at night, owls also use acoustic cues made by prey, such as rustling leaves, etc., to aid in prey capture (Payne 1971, Martin 1990). Increasing industrial noise levels negatively affect the hunting success of Northern Sawwhet Owls (Aegolius acadicus; Mason et al. 2016), and reduce the foraging efficiency of Long-eared Owls (Asio otus) and Shorteared Owls (Asioflammeus; Senzaki et al. 2016). However, a study on the nocturnal space use of Western Burrowing Owls (Athene cunicularia hypugaea) found they did not avoid areas affected by anthropogenic noise (Scobie et al. 2016). A study on Spotted Owls (Strix occidentalis) found they will flush from nests more frequently with increased proximity to a noise source (Delaney et al. 1999). Two other studies on physiological responses of Spotted Owls to anthropogenic noise found elevated fecal glucocorticoids (Hayward et al. 2011), but no detectable increase in fecal corticosterone (Tempel et al. 2003). These studies on Spotted Owls applied temporary noise stimuli, e.g., helicopters, chainsaws, or motorcycles, so it is not known how owls respond to a permanent noise source on the landscape. Increased proximity to roads and increased traffic volume has been found to decrease owl density and occupancy of sites (Hindmarch et al. 2012, Silva et al. 2012), which may be at least partially due to the masking effect of traffic noise. However, roads have several factors other than noise (vehicle collisions, pollution, etc.) that can negatively affect animal abundance and distribution (Fahrig and Rytwinski 2009), making it difficult to attribute observed effects to noise per se. Owl distribution around noisy infrastructure has not been well studied, and little is known about how chronic noise may affect the distribution of owls on the landscape. In addition to interfering with an owls' ability to detect cues from prey, industrial noise may mask owl calls, both of which are low in frequency. In the boreal forest of northern Alberta, chronic noise from industrial operations could affect habitat suitability of the surrounding area for owls, causing them to avoid the area.

Surveys to determine presence or abundance of owls often broadcast a recorded owl call to elicit a response (Clark and Anderson 1997, Grossman et al. 2008, Kissling et al. 2010). Although broadcast-call surveys can increase the probability of detecting an owl by eliciting territorial individuals to respond (Kissling et al. 2010), they are also known to draw owls into areas they might not otherwise use (e.g., Zuberogoitia et al. 2011). This could affect conclusions drawn from the results of whether an owl was using the area of interest. In addition, whether call-broadcast surveys are as effective in noisy areas in terms of whether the owls could hear the playback has not been evaluated. Passive acoustic surveys employing autonomous recording units (ARUs) set to record on a predetermined schedule, are becoming increasingly prevalent in avian research (Shonfield and Bayne 2017). ARUs have been found to be useful for surveying owls (Rognan et al. 2012) as well as other rare and elusive species (Holmes et al. 2014, 2015, Campos-Cerqueira and Aide 2016). ARUs can be left unattended in the field for extended periods, and by increasing the amount of time surveyed at a location, the likelihood that an owl occupies an area but goes undetected is reduced. Combining passive acoustic surveys with statistical methods that account for imperfect detection (occupancy models: MacKenzie et al. 2002) has been shown to be an effective approach for improving species distribution estimates for rare or threatened species (CamposCerqueira and Aide 2016). Because passive surveys are a less biased method to assess habitat use, using them in combination with occupancy models to estimate and correct for detection probability is likely the best approach for estimating owl occupancy in noisy locations.

We hypothesized that owls avoid areas near chronic industrial noise sources because they are less suitable habitat. We conducted passive acoustic surveys by deploying several ARUs per site in spring during owl breeding season in northeastern Alberta, and used automated species recognition to identify owl calls on the recordings. We estimated occupancy of Barred Owls (Strix varia), Great Horned Owls (Bubo virginianus), and Boreal Owls (Aegolius funereus) during the breeding season at sites with and without noisy infrastructure to test the prediction that occupancy is lower at noisy sites compared to quieter control sites that are unaffected by industrial noise. We tested the effect of noise on owl occupancy at two spatial scales: at the site level (larger scale), and at the level of individual ARU stations (smaller scale).

\section{METHODS}

\section{Study area}

The study area was located in the boreal forest of northeastern Alberta, within the Lower Athabasca Planning Region (LAPR). Specifically, study sites were located in upland forested areas south of Fort McMurray, north of Lac la Biche, and northwest of Cold Lake (Fig. 1). The LAPR has seen increased development in the oil and gas industry in recent years, and subsequent increases in the number of industrial noise sources on the landscape, making it a suitable area to research the potential effects of industrial noise on wildlife.

Sites were selected based on the industrial infrastructure present and grouped into three noise categories: chronic noise, intermittent noise, and no noise (Table 1). For chronic noise sites, the infrastructure present was either an in-situ oil processing plant facility or a compressor station (Table 1). The processing plants produce continuous noise at a loud level and have a large cleared area for the facilities. Compressor stations, used to pressurize oil and natural gas pipelines, produce chronic noise at a similarly loud level to the processing plants (Table 1), but have a smaller cleared area (2-4 ha). Intermittent noise sites contained a well pad accessed by a road, they had traffic noise but no industrial noise, and a similar amount of cleared forest as compressor stations. Sites with no noise contained a well pad accessed by a pipeline, they had no traffic or industrial noise, and a similar amount of cleared forest to the intermittent noise sites. Forest interior sites were not chosen as controls, because it would then be difficult to separate the effect of noise from the effect of edge habitat associated with cleared areas.

\section{Acoustic surveys}

Acoustic surveys for owls were conducted using SM2+ Song Meters (Wildlife Acoustics, Inc., Maynard, Massachusetts, USA), a commercially available autonomous recording unit (ARU). We conducted passive surveys without broadcasting calls 
Table 1. Details of the different types of sites surveyed for owls. Noise level was assessed first by listening to 3-4 recordings, the level of industrial noise was ranked by listeners using these index codes: (0) no noise, (1) low and distant, (2) moderate, and (3) very loud and close. A modal noise index was determined for each station, and a mean noise index was calculated for sites surveyed with different industrial infrastructure. Noise level was also assessed by measuring the relative noise level on both the left and right channels on 1-2 recordings from each station where there were no species vocalizing and no wind or rain on the recordings in Raven Pro version 1.5.

\begin{tabular}{|c|c|c|c|c|c|}
\hline Noise category & Infrastructure present & Noise source & Mean noise index & $\begin{array}{c}\text { Relative noise level (mean } \pm \\
\text { SE) }\end{array}$ & No. of sites \\
\hline Chronic noise & Oil processing plants & Facilities & 1.88 & $82.9 \pm 1.5 \mathrm{~dB}$ & 7 \\
\hline Chronic noise & Compressor stations & Facilities & 1.61 & $82.3 \pm 1.3 \mathrm{~dB}$ & 14 \\
\hline Intermittent noise & Well pad on road & Road traffic & 0.99 & $76.8 \pm 0.9 \mathrm{~dB}$ & 28 \\
\hline No noise & Well pad on pipeline & None & 0.48 & $74.2 \pm 0.8 \mathrm{~dB}$ & 23 \\
\hline
\end{tabular}

Fig. 1. Map of owl site locations within the Lower Athabasca Planning Region (LAPR) in northeastern Alberta. Sites were located $>3 \mathrm{~km}$ apart.

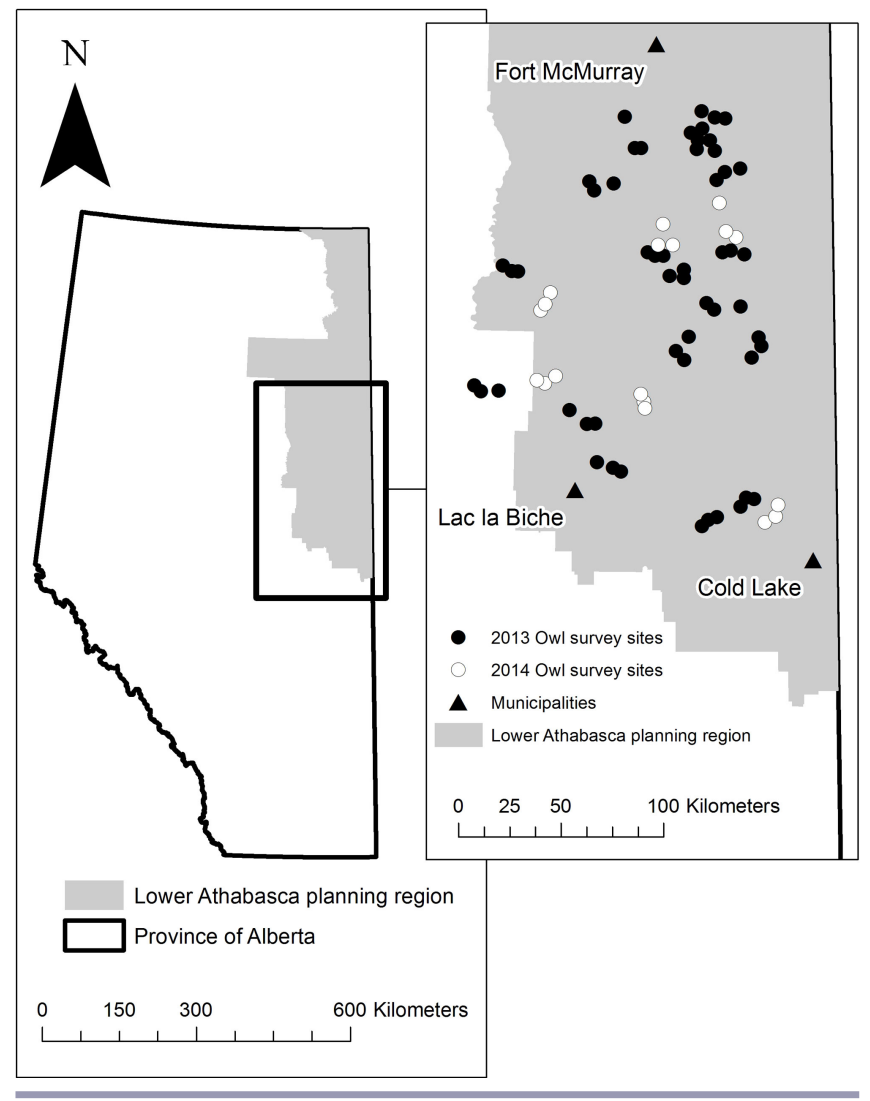

to avoid drawing in owls. We programmed each ARU to turn on and record in stereo format for 10 minutes at the start of every hour at $44.1 \mathrm{kHz}$ with a 16-bit resolution. Recording files were stored in .wac format, a loss-less audio compression format that is proprietary to Wildlife Acoustics. We tested each ARU and both microphones prior to deployment to identify any units with nonresponsive channels or degraded microphones. We used gain settings of $48 \mathrm{~dB}$ for both the left and right channel microphones. We attached ARUs at a height of approximately $1.5 \mathrm{~m}$ on trees with a smaller diameter than the width of the ARU $(18 \mathrm{~cm})$. ARUs were installed at each site for approximately two weeks in the spring, when owls are most actively calling. We surveyed 54 sites in 2013 between 18 March and 18 May, and 18 sites in 2014 between 21 March and 6 May, for a total of 72 sites. Each site consisted of 5-6 survey stations with an ARU deployed at each, with the center station closest to the noise source or well pad clearing, but still located within the forest (Fig. 2). Site size (256 ha) approximated the home range size of pairs of Barred Owls and Great Horned Owls during the breeding season (Mazur et al. 1998, Bennett and Bloom 2005, Livezey 2007).

Fig. 2. Configuration of stations within each site. One autonomous recording unit (ARU) was deployed at each station to survey acoustically for owls for approximately two weeks in the spring of 2013 and 2014. ARUs were programmed to turn on and record for 10 minutes at the start of every hour. For the two types of chronic noise sites (processing plants and compressor stations) an additional ARU (not shown) was deployed on an adjacent or opposite side of the noise source from the center (CT) ARU.

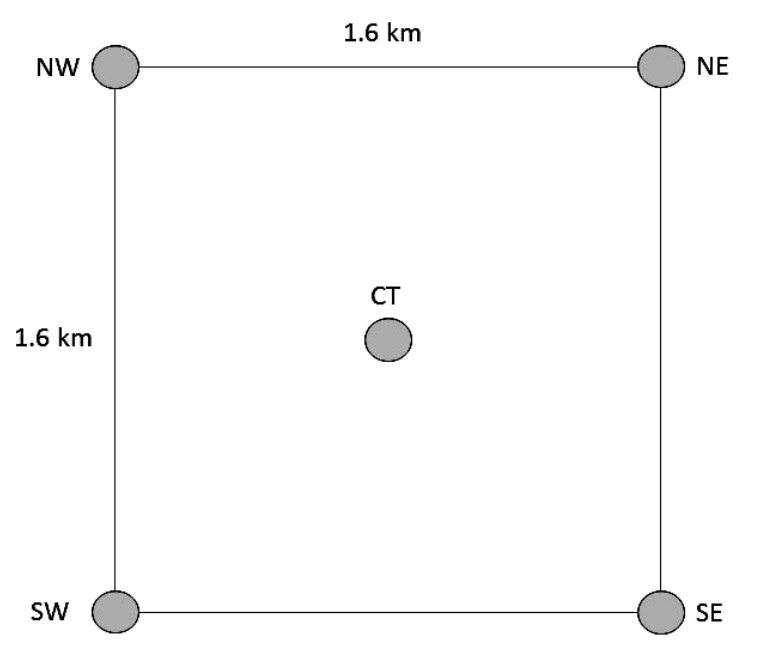

Sites with intermittent noise, and sites with no noise each had five ARU stations (Fig. 2). To address the issue of reduced detection in noisy areas, we deployed a 6th ARU near the center at sites with chronic industrial noise (processing plants and compressor stations; Table 1). The additional center ARU station was on an 
adjacent or opposite side of the noise source from the first center ARU station. We deployed the additional ARU 200-500 $\mathrm{m}$ from the center ARU to increase the area surveyed near the noise source. The variation in spacing was due to different configurations of the industrial infrastructure at each site. We assumed the detection radius of a single ARU would be reduced in noisy areas. In addition to this additional ARU, a separate experiment was conducted to estimate the detection radius of ARUs in noisy and quiet areas to compare the total area surveyed. The experiment used a speaker to simulate owls calling at increasing distances from an ARU set up near a noise source to compare the effective detection radius (Yip et al. 2017) to an ARU set up in a quiet area (see Appendix A1 for more details).

\section{Extracting acoustic data}

We used automated species recognition to efficiently process acoustic recordings to detect territorial vocalizations of Barred Owls, Great Horned Owls, and Boreal Owls. Owl calls are wellsuited to automated recognition because of little heterospecific overlap, because few other species are present or vocally active during the time of night and season when owls are calling. These three owl species were heard frequently on recordings and it was possible to obtain several representative clips of their calls. We annotated clips from field recordings in Song Scope (Wildlife Acoustics, Inc., Maynard, Massachusetts, USA) to build templates or "recognizers." We used 51 annotations of the 2phrased hoot of the Barred Owl (Odom and Mennill 2010) from 22 field recordings, 83 annotations of Great Horned Owl territorial hoots (Kinstler 2009) from 10 field recordings, and 42 annotations of the Boreal Owl trill from 8 field recordings (Table A2.1, Appendix 2). To build each recognizer, we adjusted the settings in Song Scope to improve signal detection of the annotated clips (Wildlife Acoustics 2011). We kept some settings of the recognizers consistent for all three owl species, e.g., sample rate, background filter, FFT size, and overlap (Table A2.1), but other settings were adjusted based on the specific call properties of each species, e.g., frequency and timing settings (Table A2.1). See Shonfield et al. (in press), for additional details on the performance of these three recognizers. We scanned all recordings collected in 2013 and 2014 with the three species-specific recognizers we built. Though we recorded in stereo, Song Scope scans only one channel (the left channel by default), so there are no duplicate detections resulting from detecting owl calls on each channel. Trained listeners verified all hits generated by the program to filter out false positives.

We assessed industrial noise at each ARU station using two different methods. First, we listened to recordings and ranked industrial noise on each recording based on the following index: no noise (noise code 0 ), low and distant (noise code 1 ), moderate (noise code 2), and very loud and close (noise code 3 ). We listened to the midnight recordings from three to four randomly selected dates for each station, and assigned the modal noise index for each station. Second, we measured the relative noise level on recordings in $\mathrm{dB}$ using the maximum power measurement tool in Raven Pro version 1.5 (Cornell Laboratory of Ornithology, Ithaca, New York, USA). We made measurements on both the left and right channels on one or two recordings from each station ( $\mathrm{n}=609$ recordings measured) where there were no species vocalizing and no wind or rain on the recordings.

\section{Habitat variables}

To account for differences in forest composition and human disturbance between sites, we extracted habitat variables in ArcGIS 10.3.1 (Environmental Systems Research Institute, Inc., Redlands, California, USA). We used an 800-m radius buffer around each ARU station, approximating the maximum detection radius of an ARU to detect owls calling (Yip et al. 2017). For forest composition, we calculated the percent of coniferous forest present weighted by area from the Alberta Vegetation Inventory (AVI) within each $80-\mathrm{m}$ buffer. We also calculated mean forest age weighted by area from the AVI layer, but did not include it in our models because initial analyses suggested it was not a good predictor of occupancy for any of the three owl species. This was likely due to limited variation in forest age at the locations surveyed; mean forest age around each ARU ranged from 21 to 153 years (overall mean of 93 years), 97\% of stations were surrounded by mature forest ( $50+$ years old), and $84 \%$ of stations were surrounded by old forest $(80+$ years old). For human disturbance, we calculated the proportion of human footprint in the buffer area from Alberta Biodiversity Monitoring Institute's Human Footprint layer 2012 version 3 (http://www.abmi.ca/ home/data/gis-data). Disturbances in this layer include linear features (roads, seismic lines, pipelines, transmission lines, and railways), industrial and resource extraction features (well pads, compressor stations, processing plants, mines, and other facilities), and recent forest cut blocks. For analyses at the site level, the habitat variables were extracted over the total area covered by the $800-\mathrm{m}$ buffers around each station.

\section{Analysis}

Presence/absence data derived from the automated recognizers was compiled into detection histories for each ARU station. We defined each "sampling occasion" in our detection history as a 24-hour period (a total of 24 ten-minute recordings processed by the recognizers). We had a total of nine occasions in our detection history because ARUs were deployed for a minimum of nine days. We analyzed data for each species separately at two spatial scales. The site level scale represents an owl home range, and the station level represents a smaller area surrounding an ARU. Stations with ARUs that had no acoustic data because of complete recording failures were eliminated from the dataset $(n=9)$; there were no sites where more than one ARU failed. Stations with ARUs that failed at some point during the deployment $(n=5)$ and did not record for all nine days were indicated in the detection history as "missing observations" on days that they did not record. An advantage of occupancy modeling is that it can account for "missing observations" (MacKenzie et al. 2002). At the site level, we pooled the detection histories of all ARUs within the site. At the station level, the two center ARU stations were pooled and treated as a single unit in the analysis.

Owl occupancy was modeled using "single species single season" occupancy models (MacKenzie et al. 2002) using the package "unmarked" (Fiske and Chandler 2011) in R version 3.3.1 (R Core Team 2016) with R studio version 0.99.903 (RStudio Team 2016). At the site level, we included noise category of each site as a categorical predictor variable in both the occupancy parameter and the detection parameter to assess the relative importance of industrial noise to explain both occupancy and detection probability of owls. Processing plants and compressor station sites had comparable noise levels and were both included in the 
Table 2. Comparison of occupancy models for owls at the site level ( $\mathrm{n}=72$ sites). Occupancy (psi) and detection probability ( $\mathrm{p}$ ) are modeled with noise category (NC) (chronic, intermittent, or no noise) as a factor. Percent coniferous forest (Con) and proportion of the area disturbed by humans (Dist) were included as factors to account for differences in forest composition and disturbance. The number of parameters is represented by $\mathrm{K}$. Models were evaluated based on differences between $\mathrm{AIC}_{\mathrm{c}}$ scores $\left(\Delta_{\mathrm{i}}\right)$ and $\mathrm{AIC} \mathrm{C}_{\mathrm{c}}$ weights $\left(\mathrm{w}_{\mathrm{i}}\right)$. Only the first six models with the lowest $\Delta_{\mathrm{i}}$ are reported here, $\Delta_{\mathrm{i}}$ is the difference between the observed model (i) and the best model as determined by the lowest $\mathrm{AIC}_{\mathrm{c}}$.

\begin{tabular}{|c|c|c|c|c|c|}
\hline Species & Model & $\mathrm{K}$ & $\mathrm{AIC}_{\text {。 }}$ & $\Delta_{\mathrm{i}}$ & $\mathrm{w}_{\mathrm{i}}$ \\
\hline Barred Owl $^{\dagger}$ & Psi $\left(\mathrm{NC}+\mathrm{Con}+\mathrm{Con}^{2}+\right.$ Dist $), \mathrm{p}(\mathrm{NC})$ & 9 & 341.77 & 0.00 & 0.71 \\
\hline \multirow[t]{5}{*}{ (Strix varia) } & Psi(Con + Con $^{2}+$ Dist $), p(N C)$ & 7 & 344.26 & 2.49 & 0.20 \\
\hline & Psi(NC + Con + Con $^{2}+$ Dist $), p()$. & 7 & 346.93 & 5.16 & 0.05 \\
\hline & Psi(Con + Con $^{2}+$ Dist $), p()$. & 5 & 348.69 & 6.93 & 0.02 \\
\hline & $\mathrm{Psi}\left(\mathrm{NC}+\mathrm{Con}+\mathrm{Con}^{2}\right), \mathrm{p}(\mathrm{NC})$ & 8 & 351.84 & 10.07 & $<0.01$ \\
\hline & $\operatorname{Psi}\left(\mathrm{Con}+\mathrm{Con}^{2}\right), \mathrm{p}(\mathrm{NC})$ & 5 & 353.02 & 11.25 & $<0.01$ \\
\hline Great Horned Owl & $\operatorname{Psi}(),. \mathrm{p}()$. & 2 & 710.16 & 0.00 & 0.39 \\
\hline \multirow[t]{5}{*}{ (Bubo virginianus) } & Psi(Con),p(.) & 3 & 711.88 & 1.72 & 0.16 \\
\hline & Psi(Dist), $\mathrm{p}()$. & 3 & 712.00 & 1.84 & 0.15 \\
\hline & Psi(Con + Dist),p(.) & 4 & 712.97 & 2.81 & 0.09 \\
\hline & Psi(NC),p(.) & 4 & 714.23 & 4.07 & 0.05 \\
\hline & Psi(.),p(NC) & 4 & 714.34 & 4.18 & 0.05 \\
\hline Boreal Owl & Psi(.),p(NC) & 4 & 430.47 & 0.00 & 0.45 \\
\hline \multirow[t]{5}{*}{ (Aegolius funereus) } & Psi(Con),p(NC) & 5 & 432.72 & 2.25 & 0.15 \\
\hline & Psi(Dist), $\mathrm{p}(\mathrm{NC})$ & 5 & 432.75 & 2.28 & 0.14 \\
\hline & Psi(NC),p(NC) & 6 & 433.05 & 2.58 & 0.12 \\
\hline & Psi(Con + Dist $), p(N C)$ & 6 & 435.10 & 4.63 & 0.04 \\
\hline & Psi(NC + Con $), p(N C)$ & 7 & 435.45 & 4.98 & 0.04 \\
\hline
\end{tabular}

${ }^{\dagger}$ Models for Barred Owl included a quadratic term for percent coniferous forest $\left(\mathrm{Con}^{2}\right)$ because they are known to prefer mixedwood forests.

"chronic noise" category (Table 1). The analysis at the site level included 72 sites: 21 chronic noise sites, 28 intermittent noise sites, and 23 sites with no noise (Table 1). At the station level, we ran models with noise level as a continuous predictor variable for both the occupancy parameter and the detection parameter. Initially, we ran models using the noise index, but then ran models with relative noise level measured in Raven Pro, likely a less subjective measure of noise. We present the results from the models with the relative noise level, but also discuss how these compared to results with using the noise index. Because owls are unlikely to be found consistently within the area around a single ARU station due to movement, and the same owl could be found at more than one station within a site on different sampling occasions, the occupancy estimates from models at the station level are an estimate of owl "use" (MacKenzie 2006). At the station level, a total of 353 stations were included in the analysis.

We included percent coniferous forest and proportion of the area disturbed by humans as continuous predictor variables for the occupancy parameter at both scales to account for differences in forest composition and landscape disturbance. For Barred Owls, we included a quadratic term for percent coniferous forest because previous research indicates they prefer mixedwood forests (Mazur et al. 1998, Livezey 2007, Russell 2008). For Boreal Owls and Great Horned Owls, we did not include a quadratic term for percent coniferous forest because Boreal Owls prefer coniferous forests (Hayward et al. 1993, Lane et al. 2001) and Great Horned Owls are found in a wide variety of forest types (Johnsgard 2002). In the occupancy modeling literature, time of day is often included as a survey-specific variable in the detection parameter to account for differences in detectability at different times of day. We did not include time of day in our models at either scale because we surveyed during all hours of the night and then pooled the detections on a daily basis.
We used an information-theoretic approach (Burnham and Anderson 2002) for model selection. We ran 16 candidate models for each owl species at each spatial scale. We included a null model (with no variables), a global model (with all variables), and models fitted for all possible combinations of variables (percent coniferous, proportion disturbed, and noise category/relative noise level) without interactions. We ranked models using Akaike's Information Criteria for small sample sizes (AIC), and made model-averaged predictions using the R package "MuMIn" (Barton 2016). Model averaging of top models can be a robust method to obtain parameter estimates and predictions, and is recommended when the weight of the top model is less than 0.9 (Grueber et al. 2011). There are various recommendations for choosing the top model set for model averaging, for example using a cut-off of $2 \Delta \mathrm{AIC}_{\mathrm{c}}$ (Burnham and Anderson 2002), a cut-off of $6 \Delta \mathrm{AIC}_{\mathrm{c}}$ (Richards 2008), or a cut-off of $10 \Delta \mathrm{AIC}_{\mathrm{c}}$ (Bolker et al. 2009). Our primary interest was to estimate the impact of noise on owl occupancy and detection, so we chose a cut-off of $4 \Delta \mathrm{AIC}_{\mathrm{c}}$ as our top model set to try to ensure that a noise variable was included in one of the models in the top model set while not including too many models.

\section{RESULTS}

\section{Site occupancy}

Barred Owls were detected at 29 out of 72 sites, a naïve occupancy of $40 \%$. The top ranked model for Barred Owls at the site level was our global model with all variables tested (Table 2). The second ranked model differed by less than $2.5 \Delta \mathrm{AIC}_{\mathrm{c}}$ however, and did not include noise category in the occupancy parameter (Table 2), suggesting that the noise category of sites did not have a strong effect on occupancy. The predicted occupancy estimates for each category appear to differ, however the $95 \%$ confidence 
intervals are large and overlapping (Fig. 3). The occupancy estimates are higher than we might have expected, based on the fact that Barred Owls were only detected at $40 \%$ of sites. This overestimation of occupancy and the large confidence intervals likely resulted from relatively low detection probability of Barred Owls (less than 0.3; Fig. 3). The top two models both included noise category in the detection parameter (Table 2), however the predicted detection probability was only slightly lower for chronic noise sites than the other two noise categories and the $95 \%$ confidence intervals overlapped (Fig. 3).

Fig. 3. Site level model predictions of occupancy (left panels) and detection probability (right panels) for Barred Owls (Strix varia; A, B), Great Horned Owls (Bubo virginianus; C, D), and Boreal Owls (Aegolius funereus; E, F) for the three noise categories of sites. Predictions are averaged from models within $4 \Delta \mathrm{AIC}_{\mathrm{c}}$ of the top model (Table 2). For Great Horned Owls, none of the models within $4 \Delta \mathrm{AIC}_{\mathrm{c}}$ contained noise category as a factor for either the occupancy or the detection parameters. So we made predictions based on the highest ranked models containing noise category as a factor for either the occupancy or the detection parameters (Table 2). The error bars are 95\% confidence intervals. Owl photos taken by J. Shonfield.
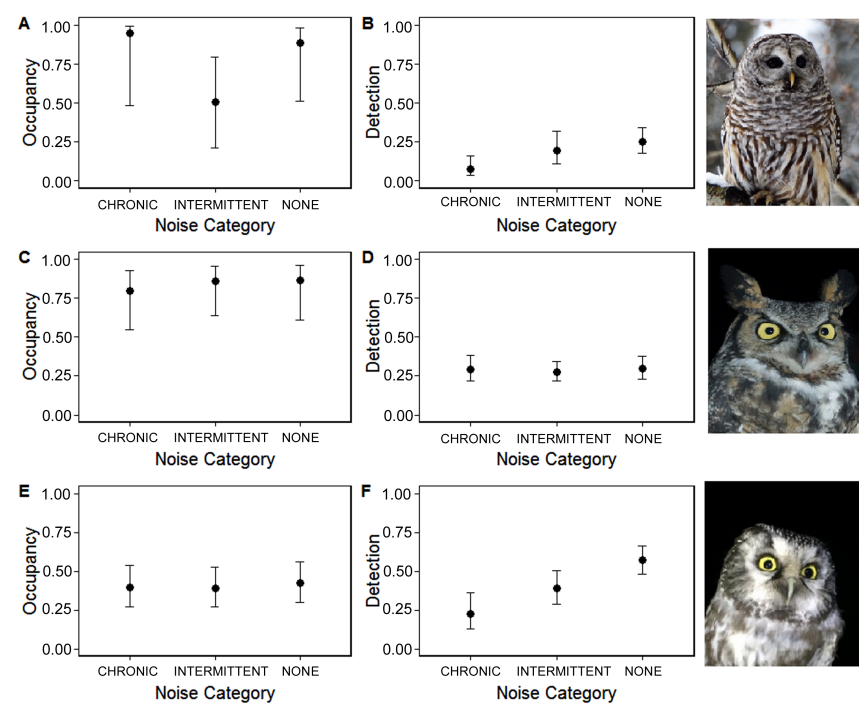

Great Horned Owls were detected at 58 out of 72 sites, a naïve occupancy of $81 \%$. The null model was the top-ranked model for Great Horned Owls, and none of the top models with a $\Delta \mathrm{AIC}_{\mathrm{c}}$ less than 4 included noise category as a factor in either the occupancy or detection parameter (Table 2). To compare Great Horned Owl occupancy across noise categories to the other owl species, we predicted occupancy from the next ranked models that included noise category as a factor in the occupancy and in the detection parameter (Table 2). Because these models had a low weight of evidence, it was not surprising that we found no effect of noise category of the site on Great Horned Owl occupancy or on detection probability (Fig. 3).

Boreal Owls were detected at 28 out of 72 sites, a naïve occupancy of $39 \%$. Noise category of the site was included as a factor in the occupancy parameter for only one of the top models (Table 2), and we found that the predicted occupancy of sites by Boreal
Owls was similar across noise categories (Fig. 3). Noise category was included in the detection parameter in all the top models (Table 2), and the predicted detection probability for Boreal Owls was highest for sites without noise and lowest for sites with chronic noise (Fig. 3).

Forest composition varied between sites from $10 \%$ to $94 \%$ coniferous forest with a mean of $48 \%$, and proportion of the area disturbed by humans ranged from 0.02 to 0.71 with a mean of 0.23. For Barred Owls, percent coniferous forest and proportion of the site disturbed were important predictors of site occupancy and were included in the top ranked models (Table 2). Barred Owls were most likely to occupy a site when the forest composition was a mix of deciduous and coniferous trees, with about $25-50 \%$ coniferous trees, and less likely to occupy sites with a greater proportion of disturbance by humans (Fig. 4). There was no effect of forest composition or human disturbance on site occupancy by Great Horned Owls or Boreal Owls (Fig. 4).

Fig. 4. Model averaged predictions (models within $4 \Delta \mathrm{AIC}_{\mathrm{c}}$ of the top model; Table 2, Table 3) for all three owl species for occupancy at two spatial scales: at the site level (top panels), and at the station level (bottom panels) as a function of forest composition ( $\%$ coniferous forest) and landscape disturbance (proportion of the area disturbed by humans resulting in loss of forest cover). The solid or dashed lines are the model averaged predictions and the colored bands are the $95 \%$ confidence intervals.
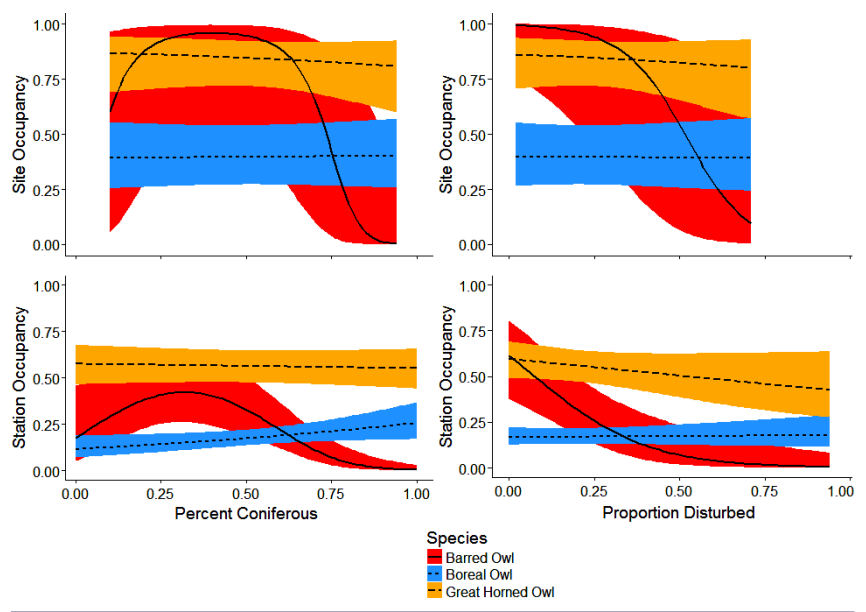

\section{Station occupancy}

Barred Owls were detected at 47 stations (13\%) across 29 sites, of these 12 sites had 2 or more stations with detections. The relative noise level of stations where Barred Owls were detected ranged between $63.5 \mathrm{~dB}$ to $92.6 \mathrm{~dB}$, with a mean ( \pm standard error) of $74.6 \mathrm{~dB} \pm 1.1 \mathrm{~dB}$. The top ranked model for Barred Owls at the station level did not include noise level as a factor for occupancy, but did contain noise level as a factor for detection probability (Table 3). We found no effect of relative noise level on station level occupancy, i.e., use, and only a slight decline in detection probability for Barred Owls as the relative noise level increased (Fig. 5). This differed from the model results using noise index, where we found a decline in station occupancy at higher noise indices. This relationship may have been primarily driven by the fact that no Barred Owls were detected at stations with a noise 
Table 3. Comparison of occupancy models for owls at the station level ( $\mathrm{n}=353$ stations). Occupancy (psi) and detection probability (p) are modeled with the relative noise level (NL) measured in Raven Pro as a factor. Percent coniferous forest (Con) and proportion of the area disturbed by humans (Dist) were included as factors to account for differences in forest composition and disturbance. The number of parameters is represented by $\mathrm{K}$. Models were evaluated based on differences between $\mathrm{AIC}_{\mathrm{c}} \mathrm{scores}\left(\Delta_{\mathrm{i}}\right)$ and $\mathrm{AIC} \mathrm{c}_{\mathrm{c}}$ weights $\left(\mathrm{w}_{\mathrm{i}}\right)$. Only the first six models with the lowest $\Delta_{\mathrm{i}}$ are reported here, $\Delta_{\mathrm{i}}$ is the difference between the observed model (i) and the best model as determined by the lowest $\mathrm{AIC}_{\mathrm{c}}$.

\begin{tabular}{|c|c|c|c|c|c|}
\hline Species & Model & $\mathrm{K}$ & $\mathrm{AIC}_{c}$ & $\Delta_{\mathrm{i}}$ & $\mathrm{w}_{\mathrm{i}}$ \\
\hline \multirow[t]{6}{*}{ Barred Owl $^{\dagger}$} & Psi(Con+Dist),p(NL) & 6 & 584.30 & 0.00 & 0.64 \\
\hline & $\mathrm{Psi}(\mathrm{NL}+\mathrm{Con}+\mathrm{Dist}), \mathrm{p}(\mathrm{NL})$ & 7 & 586.30 & 2.00 & 0.24 \\
\hline & Psi(NL+Con+Dist),p(.) & 6 & 588.10 & 3.81 & 0.10 \\
\hline & Psi(Con+Dist),p(.) & 5 & 591.33 & 7.03 & 0.02 \\
\hline & Psi(Con),p(NL) & 5 & 598.54 & 14.25 & $<0.01$ \\
\hline & Psi(NL+Con),p(SL) & 6 & 600.49 & 16.20 & $<0.01$ \\
\hline \multirow[t]{6}{*}{ Great Horned Owl } & Psi(Dist),p(.) & 3 & 1659.27 & 0.00 & 0.16 \\
\hline & Psi(.),p(.) & 2 & 1659.67 & 0.40 & 0.13 \\
\hline & Psi(.),p(NL) & 3 & 1660.23 & 0.96 & 0.10 \\
\hline & Psi(Dist),p(NL) & 4 & 1660.34 & 1.07 & 0.09 \\
\hline & Psi(Con+Dist),p(.) & 4 & 1660.65 & 1.38 & 0.08 \\
\hline & Psi(NL+Dist),p(.) & 4 & 1661.06 & 1.79 & 0.07 \\
\hline \multirow[t]{6}{*}{ Boreal Owl } & Psi(Con),p(NL) & 4 & 958.88 & 0.00 & 0.34 \\
\hline & Psi(NL+Con),p(NL) & 5 & 959.67 & 0.79 & 0.23 \\
\hline & Psi(Con+Dist),p(NL) & 5 & 960.81 & 1.93 & 0.13 \\
\hline & $\operatorname{Psi}(),. p(N L)$ & 3 & 961.40 & 2.52 & 0.10 \\
\hline & $\mathrm{Psi}(\mathrm{NL}+\mathrm{Con}+\mathrm{Dist}), \mathrm{p}(\mathrm{NL})$ & 6 & 961.69 & 2.81 & 0.08 \\
\hline & $\operatorname{Psi}(\mathrm{NL}), \mathrm{p}(\mathrm{NL})$ & 4 & 962.76 & 3.88 & 0.05 \\
\hline
\end{tabular}

${ }^{\dagger}$ Models for Barred Owl included a quadratic term for percent coniferous forest $\left(\mathrm{Con}^{2}\right)$ because they are known to prefer mixedwood forests.

Fig. 5. Station level model predictions of occupancy (left panels) and detection probability (right panels) for Barred Owls (Strix varia; A, B), Great Horned Owls (Bubo virginianus; C, D), and Boreal Owls (Aegolius funereus; E, F) across relative noise levels. Predictions are averaged from models within $4 \Delta \mathrm{AIC}_{\mathrm{c}}$ of the top model (Table 3). The solid lines are the model averaged predictions and the dashed lines are $95 \%$ confidence intervals. Owl photos by J. Shonfield.
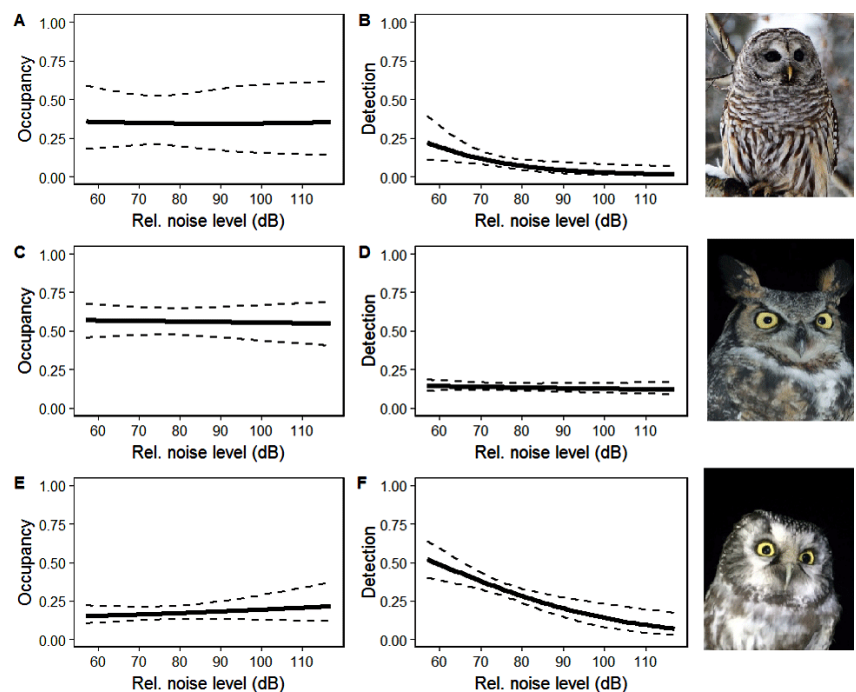

index of 2 (moderate noise) or 3 (loud noise). Though we found no effect of relative noise level on station occupancy, it is worth noting that no Barred Owls were detected at any stations with an estimated relative noise level more than $93 \mathrm{~dB}$.

Great Horned Owls were detected at 144 stations (41\%) across 58 sites, of these 42 sites had 2 or more stations with detections. The relative noise level of stations where Great Horned Owls were detected ranged between $57.8 \mathrm{~dB}$ to $110.8 \mathrm{~dB}$, with a mean $( \pm$ standard error) of $77.2 \mathrm{~dB} \pm 0.8 \mathrm{~dB}$. The null model was not the top model for Great Horned Owls but had similar support as the top model (Table 3). There was no effect of relative noise level on station level occupancy, i.e., use, or on detection probability for Great Horned Owls (Fig. 5). Boreal Owls were detected at 58 stations $(16 \%)$ across 28 sites, of these 17 sites had 2 or more stations with detections. The relative noise level of stations where Boreal Owls were detected ranged between $65.3 \mathrm{~dB}$ to $110.8 \mathrm{~dB}$, with a mean ( \pm standard error) of $77.8 \mathrm{~dB} \pm 1.3 \mathrm{~dB}$. Only one of the top models for Boreal Owls included relative noise level as a factor for occupancy, and had similar support as other models that did not include noise level (Table 3). We found no effect of noise level on station level occupancy by Boreal Owls (Fig. 5). The top models for Boreal Owls all included relative noise level as a factor for detection probability (Table 3), and we found that detection probability decreased with increasing noise levels (Fig. 5). For both Great Horned Owls and Boreal Owls, our model results using noise index were consistent with the results presented above, we found no effect of noise index on station occupancy.

From the playback experiment, we found the effective detection radius for an ARU located near a chronic noise source was roughly half the distance of an ARU in a quiet area (Table A1.1, Appendix A1). Although we deployed a second center ARU at chronic noise 
sites to increase the area sampled, it was not equal to the area sampled by ARUs in quiet areas (Table A1.1, Appendix A1). This indicates that at the station level as noise level increased, the area sampled decreased. Industrial noise levels were highest for center stations that were closest to industrial noise sources; the relative noise level (mean \pm standard error) at center stations at chronic noise sites was $93.4 \pm 2.5 \mathrm{~dB}$, whereas stations at the four corners of chronic noise sites were $79.7 \pm 0.8 \mathrm{~dB}$. The relative noise level at center stations at intermittent noise sites was $78.1 \pm 2.3 \mathrm{~dB}$, and the relative noise level at the corner stations of intermittent noise sites was $76.4 \pm 1.0 \mathrm{~dB}$. Not surprisingly, stations at sites with no noise had the lowest relative noise level, $74.2 \pm 0.8 \mathrm{~dB}$.

Forest composition varied between stations from $0 \%$ to $100 \%$ coniferous forest with a mean of $48 \%$; proportion of the area disturbed by humans varied from 0 to 0.94 with a mean of 0.18 . Station level occupancy of Barred Owls was highest when the forest was a mix of deciduous and coniferous trees and declined with increasing disturbance by humans (Fig. 4). Similar to the site level analysis, forest composition and human disturbance had no effect on Great Horned Owl station level occupancy (Fig. 4). There was no effect of human disturbance on station level occupancy of Boreal Owls, but there was a slight increase in use in more coniferous forests, though this effect was not strong (Fig. 4).

\section{DISCUSSION}

We found no evidence that occupancy of sites at a home range scale by Barred Owls, Great Horned Owls or Boreal Owls was affected by the presence of industrial noise sources or roads. We had predicted that owls would avoid noisy areas because of potential problems communicating and hunting in the presence of industrial noise, however our results indicate that owls do not avoid these areas at this large scale. This could be explained by the fact that the noise level at the edges of chronic noise sites and intermittent traffic sites was reduced to the point that in some areas it was almost inaudible, which would likely have little impact on owl communication and hunting success. In addition, there was no effect of noise from either a chronic noise source or intermittent traffic on detection probability for Barred Owls and Great Horned Owls, though detection probability was slightly higher at sites with no noise for Boreal Owls. These three owl species do not appear to avoid noise sources at the home range scale, however occupancy at this scale does not indicate how habitat use is distributed within a site. For all three species, we found that between $30-60 \%$ of sites had detections at only a single station. The noisy area in the middle of a site could create a donut shape of space use where the center is avoided, or the noise could act as a barrier where owls are only using a portion of the site.

At the station level, we found that use did not decline with relative noise level for all three owl species. Detection probability for Barred Owls and Great Horned Owls was not affected by noise level, however for Boreal Owls there was a decline in detection with increased noise. Although owl use did not decline with increased noise, the area surveyed with ARUs declined because of the decreased effective detection radius. We attempted to reduce the bias of detecting fewer owl calls in noisy locations by including noise as a factor for detection probability in our models, deploying two ARUs at the center of chronic noise sites to increase the area sampled, and also by estimating the detection radius of
ARUs in noisy areas. The effective detection radius in noisy areas was roughly half that of quiet areas, so even with two ARUs deployed at the center of the site, the sampled area was not equal to that of an ARU in a quiet location. We assumed that if owls were using noisy areas that they would move into the detection radius of the ARU and call at some point during the nine sampling days. Although not conclusive, we have some hints that Barred Owls may be more sensitive than the other species. We found that Great Horned Owls and Boreal Owls were heard calling at stations with higher noise levels compared to where Barred Owls were heard calling. This is unlikely to be due to increased masking of Barred Owl calls from the industrial noise, because their calls are slightly higher in frequency than Great Horned Owl calls but lower in frequency than Boreal Owl calls. We also found that Barred Owl use declined with increased human disturbance resulting in the loss of forest cover. The species we studied do not appear to be avoiding noisy areas, but whether these owls are tolerant of noise is not clear given that the area surveyed was smaller at noisy stations, and chronic noise seemed to differentially influence detectability between species. We may not be able to conclusively determine to what extent owls are using noisy areas at this scale unless we track their movements using other methods, e.g., transmitters.

Two recent studies have estimated hunting success and hunting efficiency of owls in the presence of anthropogenic noise (Mason et al. 2016, Senzaki et al. 2016). The conclusions of both these studies were that noise levels corresponding to $120 \mathrm{~m}$ from a road and $200 \mathrm{~m}$ from a compressor station results in reduced detection of prey (Senzaki et al. 2016) and lower capture success of prey (Mason et al. 2016). These estimates of the distance of the noise effect could explain why we did not find lower occupancy of sites by owls at either sites with intermittent traffic noise or chronic noise sources, because a relatively small proportion of the site would be within these distances from a road or industrial noise source, thus there are likely areas within a site where owls are able to hunt. Our results indicate that industrial noise does not preclude owls from occupying territories adjacent to noise sources. It would be an interesting area of future research to evaluate if occupancy rates are more variable at territories adjacent to noise sources from year to year. We found no evidence that owls are avoiding noisy areas on a smaller scale, contrary to what we would expect given the results of these studies on owl hunting success under noisy conditions (Mason et al. 2016, Senzaki et al. 2016). However, owls are unlikely to vocalize while hunting, so it is not likely we detected them in noisy areas while they were trying to hunt. A study tracking western Burrowing Owls with transmitters found that nocturnal space-use was not affected by industrial noise (Scobie et al. 2016). Future research tracking these three species of owls found in the boreal forest will be necessary to understand how these species' behavior and movement is influenced by noise sources.

The sites we surveyed varied in the amount of deciduous and coniferous forest, and in the amount of disturbance by humans. At both spatial scales, Barred Owls were more likely to be found in mixedwood forest, and less likely to be found in areas with increased disturbance by humans resulting in the loss of forest cover. Barred Owls are associated with older mixedwood forests in the northern boreal forest (Mazur et al. 1998, Russell 2008), and have been found to be most likely to occur in landscapes with 
$>66 \%$ forest cover (Grossman et al. 2008). Our results are in support of Barred Owls being habitat specialists and preferring mixedwood forests, and suggest they are sensitive to human disturbance that results in the loss of forest cover, though they do not appear to be sensitive to noise specifically. For Great Horned Owls, forest composition and human disturbance had no effect on the probability of occupancy at either scale. Great Horned Owls are generalists and are found in a wide range of habitats throughout North America (Johnsgard 2002). They may be more tolerant to disturbance, because they are often associated with heterogeneous landscapes and prevalent in landscapes with intermediate levels of forest cover (Grossman et al 2008). Our results are in support of Great Horned Owls being habitat generalists and tolerant to human disturbance. For Boreal Owls, we found no effect of forest composition on occupancy of sites, and a weak trend for Boreal Owls to use areas with more coniferous trees. Boreal Owls inhabit mixed-conifer, spruce-fir, and Douglas fir forests in western Montana, Idaho, and northwestern Wyoming (Hayward et al 1993), and mixedwood upland forest stands in Minnesota (Lane et al 2001). There was no effect of human disturbance on the occupancy of Boreal Owls at either scale.

This study is the first to look at the impact of chronic industrial noise on the distribution of three owl species in the boreal forest. Literature reviews on the effects of anthropogenic noise on wildlife have found the majority of studies documented effects from noise and suggest that noise presents a threat to species and ecosystems (Barber et al. 2010, Shannon et al. 2016). A comparative study on avian sensitivities (primarily passerines) to anthropogenic noise found that species with lower frequency vocalizations, and species with animal-based diets were more sensitive to noise (Francis 2015). Owls certainly fit this description, however we found no evidence of avoidance by owls at either scale. Species that do not show avoidance may still be negatively impacted from chronic noise, for example impacts on passerines include reduced pairing success (Habib et al. 2007) and reduced fitness (Halfwerk et al. 2011, Schroeder et al. 2012). Spotted Owls nesting near noisy roads have been found to fledge fewer young than owls nesting near quiet roads (Hayward et al. 2011). Future research should assess the reproductive success of owls living in noisy areas to determine if chronic industrial noise has other negative impacts. Our research contributes to the literature on effects of anthropogenic noise, but suggests the effect on owls is minimal, and unlikely to result in a population change.

Responses to this article can be read online at: http://www.ace-eco.org/issues/responses.php/1042

\footnotetext{
Acknowledgments:

We thank members of the Bayne lab, K. Darras, and an anonymous reviewer for helpful comments on an earlier draft of this manuscript. We thank N. Annich, M. Knaggs, A. MacPhail, L. McLeod, S. Wilson, and D. Yip for their assistance in the field. We thank $C$. Charchuk, M. Foisy, and S. Tkaczyk for their assistance developing the recognizers. We thank N. Boucher and the many students and volunteers who listened to recordings and checked the output of the
}

recognizers. We thank $H$. Lankau for organizing the field recordings and maintaining the database. Funding was supported by the National Science and Engineering Research Council, the Northern Scientific Training Program, the University of Alberta North program, the Alberta Conservation Association, the Environmental Monitoring Committee of the Lower Athabasca, Nexen Energy, and the Oil Sands Monitoring program operated jointly by Alberta Environment and Parks and Environment and Climate Change Canada.

\section{LITERATURE CITED}

Barber, J. R., K. R. Crooks, and K. M. Fristrup. 2010. The costs of chronic noise exposure for terrestrial organisms. Trends in Ecology \& Evolution 25:180-189.http://dx.doi.org/10.1016/j. tree.2009.08.002

Barton, K. 2016. MuMIn: Multi-model inference. $R$ package version 1.15.6. [online] URL: https://cran.r-project.org/package= MuMIn

Bayne, E. M., L. Habib, and S. Boutin. 2008. Impacts of chronic anthropogenic noise from energy-sector activity on abundance of songbirds in the boreal forest. Conservation Biology 22:1186-1193. http://dx.doi.org/10.1111/j.1523-1739.2008.00973.x

Bennett, J. R., and P. H. Bloom. 2005. Home range and habitat use by great horned owls (Bubo virginianus) in southern California. Journal of Raptor Research 39:119-126.

Bolker, B. M., M. E. Brooks, C. J. Clark, S. W. Geange, J. R. Poulsen, M. H. H. Stevens, and J.-S. S. White. 2009. Generalized linear mixed models: a practical guide for ecology and evolution. Trends in Ecology \& Evolution 24:127-135. http://dx.doi. org/10.1016/j.tree.2008.10.008

Brumm, H., and H. Slabbekoorn. 2005. Acoustic communication in noise. Advances in the Study of Behavior 35:151-209. http://dx. doi.org/10.1016/S0065-3454(05)35004-2

Burnham, K. P., and D. R. Anderson. 2002. Model selection and multimodel inference: a practical information-theoretic approach. Springer-Verlag, New York, New York, USA. http://dx.doi. org/10.1007/b97636

Campos-Cerqueira, M., and T. M. Aide. 2016. Improving distribution data of threatened species by combining acoustic monitoring and occupancy modelling. Methods in Ecology and Evolution 7:1340-1348. http://dx.doi.org/10.1111/2041-210X.12599

Clark, K. A., and S. H. Anderson. 1997. Temporal, climatic and lunar factors affecting owl vocalizations of western Wyoming. Journal of Raptor Research 31:358-363.

Delaney, D. K., T. G. Grubb, P. Beier, L. L. Pater, and M. Hildegard Reiser. 1999. Effects of helicopter noise on Mexican Spotted Owls. Journal of Wildlife Management 63:60-76. http:// dx.doi.org/10.2307/3802487

Fahrig, L., and T. Rytwinski. 2009. Effects of roads on animal abundance: an empirical review and synthesis. Ecology and Society 14(1):21. http://dx.doi.org/10.5751/ES-02815-140121

Fiske, I., and R. Chandler. 2011. unmarked: An R package for fitting hierarchical models of wildlife occurrence and abundance. 
Journal of Statistical Software 43:1-23. http://dx.doi. org/10.18637/jss.v043.i10

Francis, C. D. 2015. Vocal traits and diet explain avian sensitivities to anthropogenic noise. Global Change Biology 21:1809-1820. http://dx.doi.org/10.1111/gcb.12862

Francis, C. D., and J. R. Barber. 2013. A framework for understanding noise impacts on wildlife: an urgent conservation priority. Frontiers in Ecology and the Environment 11:305-313. http://dx.doi.org/10.1890/120183 http://dx.doi.org/10.1890/120183

Francis, C. D., C. P. Ortega, and A. Cruz. 2009. Noise pollution changes avian communities and species interactions. Current Biology 19:1415-1419. http://dx.doi.org/10.1016/j.cub.2009.06.052

Francis, C. D., C. P. Ortega, and A. Cruz. 2011a. Vocal frequency change reflects different responses to anthropogenic noise in two suboscine tyrant flycatchers. Proceedings of the Royal Society B 278:2025-2031. http://dx.doi.org/10.1098/rspb.2010.1847

Francis, C. D., C. P. Ortega, and A. Cruz. 2011b. Different behavioural responses to anthropogenic noise by two closely related passerine birds. Biology Letters 7:850-852. http://dx.doi. org/10.1098/rsbl.2011.0359

Grossman, S. R., S. J. Hannon, and A. Sánchez-Azofeifa. 2008. Responses of Great Horned Owls (Bubo virginianus), Barred owls (Strix varia), and Northern Saw-whet Owls (Aegolius acadicus) to forest cover and configuration in an agricultural landscape in Alberta, Canada. Canadian Journal of Zoology 86:1165-1172. http://dx.doi.org/10.1139/Z08-095

Grueber, C. E., S. Nakagawa, R. J. Laws, and I. G. Jamieson. 2011. Multimodel inference in ecology and evolution: challenges and solutions. Journal of Evolutionary Biology 24:699-711. http://dx. doi.org/10.1111/j.1420-9101.2010.02210.x

Habib, L., E. M. Bayne, and S. Boutin. 2007. Chronic industrial noise affects pairing success and age structure of Ovenbirds Seiurus aurocapilla. Journal of Applied Ecology 44:176-184. http:// dx.doi.org/10.1111/j.1365-2664.2006.01234.X

Halfwerk, W., L. J. M. Holleman, C. M. Lessells, and H. Slabbekoorn. 2011. Negative impact of traffic noise on avian reproductive success. Journal of Applied Ecology 48:210-219. http://dx.doi.org/10.1111/j.1365-2664.2010.01914.x

Hayward, G. D., P. H. Hayward, and E. O. Garton. 1993. Ecology of Boreal Owls in northern Rocky Mountains, U.S.A. Wildlife Monographs 124:3-59.

Hayward, L. S., A. E. Bowles, J. C. Ha, and S. K. Wasser. 2011. Impacts of acute and long-term vehicle exposure on physiology and reproductive success of the Northern Spotted Owl. Ecosphere 2:1-20. http://dx.doi.org/10.1890/ES10-00199.1

Hindmarch, S., E. A. Krebs, J. E. Elliott, and D. J. Green. 2012. Do landscape features predict the presence of Barn Owls in a changing agricultural landscape? Landscape and Urban Planning 107:255-262. http://dx.doi.org/10.1016/j.landurbplan.2012.06.010

Holmes, S. B., K. A. McIlwrick, and L. A. Venier. 2014. Using automated sound recording and analysis to detect bird speciesat-risk in southwestern Ontario woodlands. Wildlife Society Bulletin 38:591-598. http://dx.doi.org/10.1002/wsb.421
Holmes, S. B., K. Tuininga, K. A. McIlwrick, M. Carruthers, and E. Cobb. 2015. Using an integrated recording and sound analysis system to search for Kirtland's Warbler (Setophaga kirtlandii) in Ontario. Canadian Field-Naturalist 129:115-120. http://dx.doi. org/10.22621/cfn.v129i2.1688

Johnsgard, P. A. 2002. North American owls: biology and natural history. Second edition. Smithsonian Institution Press, Washington, D.C., USA.

Kinstler, K. A. 2009. Great Horned Owl Bubo virginianus vocalizations and associated behaviours. Ardea 97:413-420. http:// dx.doi.org/10.5253/078.097.0403

Kissling, M. L., S. B. Lewis, and G. Pendleton. 2010. Factors influencing the detectability of forest owls in southeastern Alaska. Condor 112:539-548. http://dx.doi.org/10.1525/cond.2010.090217

Lane, W. H., D. E. Andersen, and T. H. Nicholls. 2001. Distribution, abundance and habitat use of singing male Boreal Owls in northeast Minnesota. Journal of Raptor Research 35:130-140.

Livezey, K. B. 2007. Barred Owl habitat and prey: a review and synthesis of the literature. Journal of Raptor Research 41:177-201. http://dx.doi.org/10.3356/0892-1016(2007)41[177:BOHAPA]2.0.CO;2

MacKenzie, D. I. 2006. Modeling the probability of resource use: the effect of, and dealing with, detecting a species imperfectly. Journal of Wildlife Management 70:367-374. http://dx.doi. org/10.2193/0022-541X(2006)70[367:MTPORU]2.0.CO;2

MacKenzie, D. I., J. D. Nichols, G. B. Lachman, S. Droege, J. A. Royle, and C. A. Langtimm. 2002. Estimating site occupancy rates when detection probabilities are less than one. Ecology 83:2248-2255. http://dx.doi.org/10.1890/0012-9658(2002)083[2248: ESORWD]2.0.CO;2

Martin, G. 1990. Birds by night. T \& AD Poyser, London, UK.

Mason, J. T., C. J. W. McClure, and J. R. Barber. 2016. Anthropogenic noise impairs owl hunting behavior. Biological Conservation 199:29-32. http://dx.doi.org/10.1016/j.biocon.2016.04.009

Mazur, K. M., S. D. Frith, and P. C. James. 1998. Barred Owl home range and habitat selection in the boreal forest of central Saskatchewan. Auk 115:746-754. http://dx.doi.org/10.2307/4089422

McClure, C. J. W., H. E. Ware, J. Carlisle, G. Kaltenecker, and J. R. Barber. 2013. An experimental investigation into the effects of traffic noise on distributions of birds: avoiding the phantom road. Proceedings of the Royal Society B: Biological Sciences 280:20132290. http://dx.doi.org/10.1098/rspb.2013.2290

Odom, K. J., and D. J. Mennill. 2010. A quantitative description of the vocalizations and vocal activity of the Barred Owl. Condor 112:549-560. http://dx.doi.org/10.1525/cond.2010.090163

Payne, R. S. 1971. Acoustic location of prey by Barn Owls (Tyto alba). Journal of Experimental Biology 54:535-573.

R Core Team. 2016. R: A language and environment for statistical computing. R Foundation for Statistical Computing, Vienna, Austria. [online] URL: https://www.R-project.org/

Richards, S. A. 2008. Dealing with overdispersed count data in applied ecology. Journal of Applied Ecology 45:218-227. http://dx. doi.org/10.1111/j.1365-2664.2007.01377.x 
Rognan, C. B., J. M. Szewczak, and M. L. Morrison. 2012. Autonomous recording of Great Gray Owls in the Sierra Nevada. Northwestern Naturalist 93:138-144. http://dx.doi.org/10.1898/ nwn11-02.1

RStudio Team. 2016. RStudio: integrated development for $R$. RStudio, Inc., Boston, Massachusetts, USA. [online] URL: http://www.rstudio.com/

Russell, M. S. 2008. Habitat selection of Barred Owls (Strix varia) across multiple scales in a boreal agricultural landscape in northcentral Alberta. Thesis. University of Alberta, Edmonton, Alberta, Canada.

Schroeder, J., S. Nakagawa, I. R. Cleasby, and T. Burke. 2012. Passerine birds breeding under chronic noise experience reduced fitness. PLoS ONE 7:e39200.http://dx.doi.org/10.1371/journal. pone. 0039200

Scobie, C., E. M. Bayne, and T. Wellicome. 2016. Influence of human footprint and sensory disturbances on night-time space use of an owl. Endangered Species Research 31:75-86. http://dx. doi.org/10.3354/esr00756

Senzaki, M., Y. Yamaura, C. D. Francis, and F. Nakamura. 2016. Traffic noise reduces foraging efficiency in wild owls. Scientific Reports 6:30602. http://dx.doi.org/10.1038/srep30602

Shannon, G., M. F. McKenna, L. M. Angeloni, K. R. Crooks, K. M. Fristrup, E. Brown, K. A. Warner, M. D. Nelson, C. White, J. Briggs, S. McFarland, and G. Wittemyer. 2016. A synthesis of two decades of research documenting the effects of noise on wildlife. Biological Reviews 91:982-1005. http://dx.doi.org/10.1111/ brv. 12207

Shonfield, J., and E. M. Bayne. 2017. Autonomous recording units in avian ecological research: current use and future applications. Avian Conservation and Ecology 12(1):14. http://dx.doi. org/10.5751/ACE-00974-120114

Shonfield, J., S. Heemskerk, and E. M. Bayne. In press. Utility of automated species recognition for owl acoustic monitoring. Journal of Raptor Research.

Silva, C. C., R. Lourenço, S. Godinho, E. Gomes, H. SabinoMarques, D. Medinas, V. Neves, C. Silva, J. E. Rabaça, and A. Mira. 2012. Major roads have a negative impact on the Tawny Owl Strix aluco and the Little Owl Athene noctua populations. Acta Ornithologica 47:47-54. http://dx.doi.org/10.3161/0001645$12 \times 653917$

Slabbekoorn, H., and M. Peet. 2003. Birds sing at a higher pitch in urban noise. Nature 424:267. http://dx.doi.org/10.1038/424267a

Tempel, D. J., R. J. Gutierrez, and R. J. Gutiérrez. 2003. Fecal corticosterone levels in California Spotted Owls exposed to lowintensity chainsaw sound. Wildlife Society Bulletin 31:698-702.
Wildlife Acoustics. 2011. Song Scope bioacoustics software 4.0 user's manual. Wildlife Acoustics Inc., Maynard, Massachusetts, USA. [online] URL: https://www.wildlifeacoustics.com/images/ documentation/Song-Scope-Users-Manual.pdf

Yip, D. A., E. M. Bayne, P. Sólymos, J. Campbell, and D. Proppe. 2017. Sound attenuation in forested and roadside environments: implications for avian point count surveys. Condor 119:73-84. http://dx.doi.org/10.1650/CONDOR-16-93.1

Zuberogoitia, I., J. Zabala, and J. E. Martínez. 2011. Bias in Little Owl population estimates using playback techniques during surveys. Animal Biodiversity and Conservation 34:395-400.
Editor-in-Chief: Keith A.Hobson Subject Editor: André Desrochers
Sponsored by the Society of Canadian Ornithologists and Bird Studies Canada Parrainée par la Société des ornithologistes du Canada et Études d'oiseaux Canada

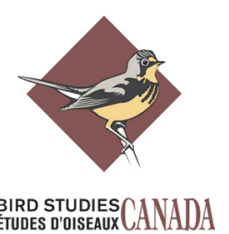


Appendix 1. Estimating the effective detection radius for autonomous recording units under noisy conditions

\section{Playback methods}

To estimate how far we could hear owls on autonomous recording units (ARUs) in noisy areas compared to quiet areas, we broadcast owl calls from a speaker at different distances from the ARU along 5 control transects and 5 noisy transects between November 25 and December 5, 2014. Control transects were located in forested areas unaffected by road or traffic noise. Noisy transects extended away from a compressor station. Using the same methods and equipment as Yip et al. (2017), we broadcast recorded owl calls using an Alpine digital CD Receiver (CDE-122) connected to an Alpine 6.5 -inch speaker and tweeter set (SPR-60) contained within a wooden box $(25 \times 29 \times 38 \mathrm{~cm})$. The speaker was attached to a tripod at a height of 1.5 metres, a height similar to other avian playback studies (Koloff and Mennill, 2013; Sandoval et al., 2015). The speaker faced the ARU and broadcast calls at 30 standardized distances ranging from 12 to 1,312 meters measured using a handheld GPS unit (GARMIN GPSmap 78, accuracy $\pm 3 \mathrm{~m}$ ). For both noisy and quiet transects, a single ARU (an SM2+ Song Meter by Wildlife Acoustics, Inc., Maynard, Massachusetts, USA) was attached at a height of approximately $1.5 \mathrm{~m}$ on trees with a smaller diameter than the width of the ARU $(18 \mathrm{~cm})$. The ARU was set to record continuously in stereo format at $44.1 \mathrm{kHz}$ with a 16-bit resolution. The ARU remained stationary and the speaker was moved to each distance interval to simulate an owl calling from increasing distances from the ARU. For noisy transects the ARU was positioned approximately $100 \mathrm{~m}$ from a compressor station.

Owl calls were broadcast in the following order: Northern Saw-whet Owl (Aegolius acadicus), Boreal Owl (Aegolius funereus), Great Gray Owl (Strix nebulosa), Long-eared Owl (Asio otus), and Barred Owl (Strix varia). We used a two second interval between calls to avoid signal overlap. This sequence was broadcast at a sound pressure level of $90 \mathrm{~dB}$ (re $20 \mu \mathrm{Pa}$ ) which we normalized using Adobe Audition CS6 (Adobe Systems Inc., San Jose, California, USA) and calibrated using a handheld sound level meter (Sper Scientific 840018 ) by measuring a $1000 \mathrm{~Hz}$ pure tone one meter from the speaker (based on fast-time A-weighting). We used Adobe Audition CS6 to generate the $1000 \mathrm{~Hz}$ pure tone. Although we broadcast owl calls at $90 \mathrm{~dB}$, we do not know how closely this reflects the real sound level of owl calls. This information is difficult to obtain and there is little published on this for any avian species, thus we acknowledge that this method can only determine relative differences in detection distances between noisy and quiet areas.

\section{Sound Processing}

Recorded playbacks were extracted from recordings using Adobe Audition CS6. Owl calls from each sequence were clipped into individual sound files $(\mathrm{n}=1070)$ using an automated script and the 'textgrid' function in Praat V5.4.06 (Boersma and Weenink, 2015). These clips were randomized and joined together in sets of 10 sounds with 2 second spacing to create a single sequence of randomized sounds using an automated batch script. These sequences were given to 2 trained observers who identified sounds by listening to the recordings at standardized volume levels and from visually scanning spectrograms in Adobe Audition CS6 (window type: Blackman-Harris; window length: 2048). Volume levels were selected to maximize amplitude and detections while avoiding any risk of hearing damage. Fifteen percent of sounds were blank ambient background sound consisting of low levels of wind and vegetation noise normally present in recordings to control for false positive identifications. Randomization of sounds removed an observer's ability to predict which sounds would occur in what order although observers were aware of all possible species that could be presented. 
We used a half-normal detection function to calculate Effective Detection Radius (EDR) using the same approach as Yip et al. (2017). EDR is the parameter, $\tau$, in the half-normal detection function: $p(d)=\exp \left(-d^{2} / \tau^{2}\right)$. EDR is defined as the distance at which number of individual birds detected outside $\tau$ is equal to the number of missed individuals within $\tau$. We ran generalized linear models (GLMs) with a fixed intercept at 0 , complimentary log-log link function, and binomial distribution. Interaction with distance was included in models for all parameters of interest but main effects were excluded to accommodate a fixed intercept. This allowed us to calculate EDR using a linear modelling framework. We transformed distance to $\mathrm{x}=-\mathrm{d}^{2}$ before modelling so that distance was a linear predictor. We estimated EDR for all species (Table A1.1) by summing the beta coefficients of variables related to distance in our best models $(\beta)$. We calculated EDR using: $\tau=(1 / \beta)^{0.5}$.

Table A1.1. Estimated effective detection radius (EDR), lower and upper 90\% confidence intervals (CI) and the estimated area sampled by an autonomous recording unit (ARU) for the territorial calls of five species of owls in loud and quiet conditions.

\begin{tabular}{lccccc}
\hline \hline \multirow{2}{*}{ Species } & & Lower 90\% & Upper 90\% & \multicolumn{2}{c}{$\begin{array}{c}\text { Area sampled } \\
\text { (ha) }\end{array}$} \\
\hline Barred Owl & Conditions & EDR $(\mathrm{m})$ & CI & CI & 15.42 \\
Boreal Owl & Loud & 221.54 & 185.49 & 261.38 & 75.95 \\
& Quiet & 491.68 & 391.57 & 609.35 & 10.16 \\
Great Gray Owl & Loud & 179.81 & 146.51 & 211.75 & 69.00 \\
& Quiet & 468.64 & 375.90 & 576.41 & 13.02 \\
Long-eared Owl & Loud & 203.61 & 167.79 & 239.40 & 143.43 \\
& Quiet & 675.69 & 517.15 & 936.22 & 11.34 \\
Northern Saw-whet Owl & Loud & 189.95 & 158.62 & 219.33 & 47.99 \\
& Quiet & 390.83 & 313.52 & 473.48 & 24.14 \\
& Loud & 277.22 & 232.39 & 338.04 & 61.62 \\
\hline
\end{tabular}

\section{LITERATURE CITED}

Boersma, P., and D. Weenink. 2015. Praat: doing phonetics by computer. University of Amsterdam, Amsterdam, NL. [online] URL: http://www.fon.hum.uva.nl/praat/

Koloff, J., and D. J. Mennill. 2013. The responses of duetting antbirds to stereo duet playback provide support for the joint territory defence hypothesis. Ethology 119:462-471. http://dx.doi.org/10.1111/eth.12084

Sandoval, L., T. Dabelsteen, and D. J. Mennill. 2015. Transmission characteristics of solo songs and duets in a neotropical thicket habitat specialist bird. Bioacoustics 24:289-306. http://dx.doi.org/10.1080/09524622.2015.1076346

Yip, D. A., E. M. Bayne, P. Sólymos, J. Campbell, and D. Proppe. 2017. Sound attenuation in forested and roadside environments: implications for avian point count surveys. The Condor 119:73-84.

http://dx.doi.org/10.1650/CONDOR-16-93.1 
Appendix 2. Details on the recognizers used to detect owl calls

Table A2.1. Details of the settings, annotations, and performance statistics of the automated computer recognizers built in Song Scope (Wildlife Acoustics Inc., Maynard, Massachusetts, USA) to detect calls of Barred Owls (Strix varia), Great Horned Owls (Bubo virginianus), and Boreal Owls (Aegolius funereus).

\begin{tabular}{|c|c|c|c|}
\hline Recognizer settings & Barred Owl & Great Horned Owl & Boreal Owl \\
\hline Min. quality $\dagger$ & 50 & 50 & 50 \\
\hline Min. score $\neq$ & 60 & 60 & 60 \\
\hline Sample rate $(\mathrm{Hz})$ & 16,000 & 16,000 & 16,000 \\
\hline Max. complexity § & 32 & 31 & 32 \\
\hline Max. resolution | & 7 & 10 & 7 \\
\hline FFT size $\mathbb{I}$ & 512 & 512 & 512 \\
\hline FFT overlap \# & 0.5 & 0.5 & 0.5 \\
\hline Frequency minimum $(\mathrm{Hz})$ & 312.5 & 187.5 & 468.75 \\
\hline Frequency range $(\mathrm{Hz})$ & 1250 & 1125 & 1250 \\
\hline Amplitude gain (dB) & 0 & 0 & 0 \\
\hline Background filter (s) & 1 & 1 & 1 \\
\hline Max. syllable length (ms) & 784 & 496 & 288 \\
\hline Max. syllable gap (ms) & 928 & 1008 & 400 \\
\hline Max. song length (ms) & 4016 & 3040 & 4048 \\
\hline Dynamic range $(\mathrm{dB})$ & 10 & 15 & 15 \\
\hline Algorithm & 2.0 & 2.0 & 2.0 \\
\hline No. of annotations used & 51 & 83 & 42 \\
\hline Sources for annotations & $\begin{array}{l}22 \text { field recordings } \\
\text { from } 17 \text { different } \\
\text { point locations in } \\
\text { NE Alberta }\end{array}$ & $\begin{array}{l}10 \text { field recordings } \\
\text { from } 8 \text { different } \\
\text { point locations in } \\
\text { NE Alberta }\end{array}$ & $\begin{array}{c}8 \text { field recordings } \\
\text { from } 7 \text { different } \\
\text { point locations in } \\
\text { NE Alberta }\end{array}$ \\
\hline \multicolumn{4}{|c|}{ Recognizer performance statistics } \\
\hline Cross training $(\% \pm \mathrm{SE})$ & $74.49 \pm 4.96$ & $79.78 \pm 3.07$ & $80.07 \pm 5.97$ \\
\hline Total training $(\% \pm \mathrm{SE})$ & $74.16 \pm 3.43$ & $79.98 \pm 2.88$ & $81.71 \pm 4.98$ \\
\hline Model states & 27 & 23 & 23 \\
\hline State usage & $11 \pm 6$ & $8 \pm 2$ & $5 \pm 3$ \\
\hline Feature vector & 7 & 10 & 7 \\
\hline Mean symbols (n) & $30 \pm 24$ & $21 \pm 8$ & $19 \pm 11$ \\
\hline Syllable types & 8 & 7 & 8 \\
\hline Mean duration of syllable (s) & $2.64 \pm 0.67$ & $2.06 \pm 0.35$ & $1.20 \pm 0.30$ \\
\hline
\end{tabular}

$\uparrow$ Quality values range from 0 to 100 and indicate signal quality confidence

₹ Score values range from 0 to 100 and indicate percent match with recognizer

$\S$ Number of states used to generate the model for the recognizer

| Size of feature vectors in the recognizer

II Number of sampled used by the Fast Fourier Transform algorithm to generate a recognizer

\# Amount of overlap between each Fast Fourier Transform window 